\title{
Urban Planning in Al-Madinah Al-Munawarah using New Green Spaces Modelling through GIS Application
}

\author{
Aljohani Nadiyah Mazi ${ }^{*}$, Mokhtar Jaafar ${ }^{2}$ and Lam Kuok Choy ${ }^{3}$ \\ ${ }^{1,2,3}$ Geography Program, Centre for Research in Development, Social \& Environment, UKM, Malaysia
}

Received: 2021-05-01 Accepted: 2021-05-01

Keywords:

green spaces,;

urban planning;

public parks;

mental health;

Al-Madinah Al-Munawarah

Correspondent email:

nadia105@windowslive.com

\begin{abstract}
The present study investigated the new green spaces modelling in Al-Madinah Al-Munawarah using GIS application. It adopted the mental health theory as a theoretical framework. The data of the study was collected through two data collection instruments, namely, questionnaire as well as interview. The quantitative data was analysed through SPSS software while the qualitative data collected from the interviews was qualitatively analysed using thematic content analysis. The findings of the study revealed the most suitable model for potential new green spaces using GIS analysis (descriptive summaries) for urban planning in Al-Madinah Al-Munawarah is Quba (25.5\%). Moreover, the most prominent challenge facing the design of a new green space in Al-Medinah Al-Munawarah, Saudi Arabia, is the weakness of the budget allocated to designing green spaces (86.7\%). It is also shown that the most prominent benefits of designing new green spaces for the residents of Al-Madinah Al-Munawarah are the provision of seats and seating areas. Therefore, the participants stress the importance of taking into account the provision of seats and seating places when designing green spaces (93.3\%). In terms of the potential of developing urban green spaces in Al-Madinah $\mathrm{Al}$ -Munawarah, the majority of the respondents believe that urban green spaces can be developed, to a large degree, in Al-Madinah Al-Munawarah in the future. Therefore, the study recommends that urban green spaces should be developed in Al-Madinah Al-Munawarah and the budget allocated to designing green spaces in Al-Madinah Al-Munawarah should be also increased. This study could be considered as a guideline for future development that can be used by government in Saudi Arabia.
\end{abstract}

2021 by the authors. Licensee Indonesian Journal of Geography, Indonesia

(1) Commons

Attribution(CC BY NC) licensehttps://creativecommons.org/licenses/by-nc/4.0/.

\section{Introduction}

Green space has a great impact on human development. Literature (e.g. McPhearson et al., 2015; Vieira et al., 2018) revealed that green space with flowers and trees have their positive impact on humans. For instance, green space might decrease human tensions and spread the psychological peace among them. Besides, it is maintained that the green space reduces the desert areas in cities (Al-Ballaa et al., 2012) and increases the productivity of employees (Mytton et al., 2012). It also gives a sense of revitalization as a result of reducing boredom resulting from the urban planning as well as fixed lines of buildings and walls (Barbosa et al., 2007). Moreover, Barton and Pretty (2010) claimed that green space minimizes the negative impact of urbanization and improves the people and employees' physical and mental activities.

Furthermore, the green space has become essential in the governmental building and any formal places. Mytton (2012) reveals that the productivity of the employee has been increased if the workplace has permeant greenery and beautiful landscape. The green space gives a sense of revitalization as a result of reducing boredom resulting from the urban planning and fixed lines of buildings and walls (Barbosa, 2007). In this respect, Barton (2010) contended that green space reduces the negative effects of urbanization and improves the physical and mental activities of people and employees as well. Hillsdon (2009) explores that green space also allows providing huge socioeconomic benefits like restitution. Green space also encourages to attract more tourist to visit parks. Onder (2011) reveals that the annual revenues of the tourism sector will be increasing due to the spread of green space.It is worth mentioning that as cities grow, changes in urban land cover as well as geometry, morphology and architecture coupled with intensifying human activities have led to a modified thermal climate (Neema \& Ohgai, 2013; Safrilia \& Poerwoningsih, 2021). AlMadinah Al-Munawarah was not planned around a goal of ecological resilience; this includes less early planning in terms of green spaces, parks, and other natural resources. Furthermore, Al-Madinah Al-Munawarah has been listed as one of the fastest-growing cities in Saudi Arabia, with new industries and jobs being moved to the Al-Madinah AlMunawarah area (Metwaly et al., 2021). This urban growth appears to be on a trajectory to continue, leading to an increased need to provide reasonable access to green spaces for all residents.

The demand of green space has increased in Al-Madinah $\mathrm{Al}$-Munawarah due to the increase in the population destiny. Therefore, establishing new cities in Al-Madinah AlMunawarah is the main goal of the Saudi authorities (The Report Saudi Arabia, 2020) and therefore, there should be adequate financial support allocated for reaching this aim. More importantly, the current status of new cities in AlMadinah Al-Munawarah is unplanned due to the destiny of 
the population. Hence, the green space in this city is not enough for the residents. Moreover, informal settlements lead to an increase in the phenomenon of environmental degradation in Al-Madinah Al-Munawarah (Metwaly et al., 2021). The insufficient financial support to redesign green spaces in the annual planning also leads to the failure to meet the public demands of green spaces. Hence, the social problems will increase in this city. On the other hand, AlMadinah Al-Munawarah is a unique city in Saudi Arabia due to its Islamic significance. Consequently, it is under observation of the Saudi authorities that aim to design new green spaces for improving the standard of living for the residents (The Report Saudi Arabia, 2020).

Additionally, the green space allows promoting the socioeconomic advantages for individuals and groups in order to increase sustainable development (Chiari \& Seeland, 2004; Barton \& Pretty 2010). Because of its importance, the concerned authorities should have enough information about green spaces in their cities. In this respect, Abebe \& Megento (2017) pointed out that the GIS could be an effective tool that offer full information about the green spaces as well as the appropriate places where green spaces could be developed. Through sensing techniques, GIS can determine the suitable places which are potential to be green spaces.

Recently, the application of Geographic Information Systems (GIS) in the studies of urban green space areas has been increasing in numbers. GIS software breakthrough technology helps users discover new things about their investments and risks, reduces the cost of manual maintenance of the maps and allows the simultaneous assessment of technical, financial and environmental factors (Mobasheri et al, 2020). GIS has been also proven to be a workable system to connect database information such as billing, material account, distribution analysis and outage reporting in power utility (ibid). GIS are now being used widely for the mapping and modelling of utility network systems. Users utilise network models to monitor and analyse their distribution systems.

Furthermore, GIS is used to identify green space areas with high ecological, recreational and aesthetic values to protect certain green space areas from development, to present a GIS-based decision support tool to model planning scenarios related to the creation of new green space areas as part of greening strategies, to quantify the spatial configuration of green spaces that are used in landscape metrics, to assess the accessibility of many proposed green spaces enhancements, to implement a web-based platform and to analyse the delineation of distance-based catchment areas (Unal, 2014). Furthermore, GIS has been a useful tool for measuring accessibility to parks in terms of supply and demand. Some of the main research fields cover the identification of areas suffering from a lack of accessibility.

In fact, many scholars discussed the positive side of GIS. GIS made the clearance view of green space in several cities. For instance, Rahnama and Akbari (2013) presents the information that allow to design new accuracy map about green space in the cities. They also confirmed the abilities of geographical information system to determine the green space in the new cities.

Moreover, Rahnama and Akbari (2013) contended that green space is important for ecological and aesthetic for new cities. She also argued that GIS presents green space accuracy and could be used to assess green space in the society.
Through using internet and other developed programs, GIS can assess the benefits of green space.

Besides, green space faced many challenges in the last decades especially when establishing new cities. Sometimes planning does not consider the values of green space and reduce the green area. In addition, the vision of achieving profit first without taking into consideration the customization green space for new cities (Panduro \& Veie, 2013). The danger of minimizing green space increases the rate of anxious and terrible of human behaviour. Additionally, the minimization of the green space leads to the increase in the dioxide and the decrease in the rate of the fresh air from the city. Nevertheless, without green space the other companies will have negative effects on reducing demand of green landscape products like trees, bushes, green hedges and landscapes.

More significantly, ignoring the significant role of green space in human activities has a negative impact on the laziness and disappointed feelings. The minimization of green space also leads to injustice toward the poor people. Although there are some obstacles facing green space, the urban planning happened positively to maintain the civilization development and rights of human life (Pojani \& Maci, 2015).

Although it is vitally significant to provide accurate data about green spaces for the concerned authorities, GIS encounters some challenges in terms of collecting sufficient data related to places which are potential to be green space. A handful of studies have been conducted to investigate the green spaces in Saudi Arabia. For instance, Al-Sharif (2002) investigated the urban change in Makkah Al-Mukarramah where the modern urban environment of the city was divided into three areas known as traditional and transitional stage as well as modern growth areas. As far as the authors know, there is no study examining the green spaces as well as the urban planning in Al-Madinah Al-Munawarah, Saudi Arabia. Consequently, the green space is essential for human development (Barton, 2010). The green space allows promoting the socio-economic for individuals and groups for improving sustainable development (Chiari, 2004). Abebe et al., (2017) was assessed suitable sites for urban green space using geographic information system (GIS) multicriteria analysis methods. Numerous spatial and non-spatial datasets were obtained from different organizations and processed using GIS tools and remote sensing techniques for a suitable site selection process. The suitability analysis was done in GIS -based multi-criteria decision analysis steps. Al-Sharif (2002) attempted to study the urban change in Makkah $\mathrm{Al}$ Mukarramah, in which he divided the modern urban environment of the city into three areas: the traditional area, the transitional stage area, the modern growth area.Due to the lack of green spaces surrounding the area of Al-Madinah Al-Munawarah, the tendency of man-made urban expansion and the absence of the specific model being applied on green spaces in urban planning leads to the need to study the best model of urban green spaces planning in the study area. Therefore, this study investigates the green spaces using GIS for urban planning in Al-Madinah Al-Munawarah, Saudi Arabia, the most suitable model for green spaces, the challenges facing the design of green spaces and the usefulness of green spaces for residents of Al-Madinah AlMunawarah, Saudi Arabia. It answers the following research questions: 
1. What are the most suitable models for potential new green spaces using GIS analysis for urban planning in $\mathrm{Al}$ -Madinah Al-Munawarah, Saudi Arabia?

2. What are the challenges of designing a new green space area in Al-Madinah Al-Munawarah, Saudi Arabia?

How can designed new green spaces be useful for the residents of Al-Madinah Al-Munawarah in Saudi Arabia? It is expected that the findings of the present study would be useful as they contribute to developing new green spaces in Al-Madinah Al-Munawarah. This study could have an influence on decision making regarding the urban planning in Al-Madinah Al-Munawarah, Saudi Arabia. Consequently, it could be said that the current study can be considered as a guideline for future development that can be used by government in Saudi Arabia. It might also provide useful implications for interested researchers in Saudi Arabia and perhaps in other similar context.

There is no doubt that urban planning is very essential in society. Rupprecht and Byrne (2015) pointed out that the residents should contribute to designing the new cities through the concept of mental health. This theory also has a significant contribution in highlighting the role of planning new cities and the effects of the green space in designing such cities allowing to take per capita in green space into consideration. The followers of this theory claim that the green space is very essential for the mental human health. They also believe that the unmoral problems resulting from reducing green space particularly in the industrial cities with favour expand the industrial planning.

Moreover, this theory adopts the idea of dividing the lands into several areas taking into consideration the green space to maintain the beliefs and norms of the residents' new cities. However, planning new cities faced several stages. In all stages, the planning can allow redesigning green space to provide the facilities for the residents. This theory absence that the old cities or Islamic cities like Al-Madinah AlMunawarah need to redesign green space particularly in the new cities so as develop the standard of living in these cities. General mental health requires being in contact with natural environments (Wolf \& Robbins, 2015). In more recent studies, green spaces have been reported to cause less levels of frustrations and stress (Alcock et al., 2013), and residents in cities with lush greenery had better mental health compared to those living in less green environments (Leslie et al., 2008). Along with these findings are those reported by other similar studies, which showed residents in high quality green neighbourhoods had lower levels of psychosocial distress compared to those living in low-quality open spaces. Moreover, gardens have been known to lower depression among the elderly who use them for relaxation and walking (Hanson et al., 2010). People's depressed moods were rectified by walking in nature (Kross et al., 2012).

Moving on to mental function and concentration, Wolf and Robbins (2015) found that the exposure to the nature could lead to heightened task attention and focus, and in the workplace context, the presence of plants has been revealed to enhance the morale, efficiency, satisfaction among employees while decreasing their absenteeism and sick leave (Wolf \& Robbins, 2015). In contrast, employees who work in the offices with no nature views and indoor plants have been reported to have higher tension and anxiety levels (Chang, Li\& Chen, 2005).
The present study adopts the Mental Health Theory because it highlights the role of planning new cities and the impact of green spaces in designing such new cities. It also stresses the importance of green space and its role in the mental health of human residents. Since this theory adopts the idea of dividing the lands into several areas taking into consideration the green space to maintain the beliefs of the residents' new cities, Al-Madinah Al-Munawarah, the context of this study is studies at the municipal level where seven municipalities are investigated.

\section{Methods}

This section discusses the study design, population and sampling, data collecting instruments, and the theoretical framework of the present study.

\section{The study context}

This study is carried out in Al-Madinah Al-Munawarah, Saudi Arabia. It also has an area of $151,990 \mathrm{~km}$. It is worth noting that there are 74 green parks in the city. Moreover, the total area of the green park space is 1.246.186.362 $\mathrm{m}^{2}$. Moreover, the total of green lands in Al-Madinah AlMunawarah, Saudi Arabia, is $800.000 \mathrm{~m}^{2}$. This indicator includes the bushes, green lands, streets and parks in the national transformation program 2020. In addition, the total green space in Al-Madinah Al-Munawarah, Saudi Arabia, will be improved to be $1.200 .000 \mathrm{~m}^{2}$ in 2020 . This city is which is particularly chosen because it is a prominent Islamic destination for all Muslims all over the globe. Figure (1) shows the images of the map of Al-Madinah Al-Munawarah, Saudi Arabia.

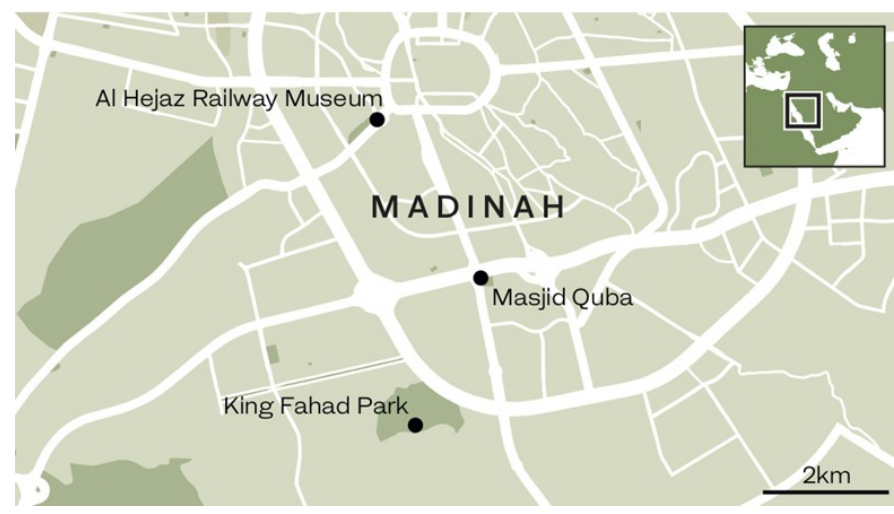

Figure 1. Al-Madinah Al-Munawarah Map

Study design and sampling

This study adopts both quantitative and qualitative approach for selecting and analyzing the data of the study; the data was gathered through using questionnaire and interviews. This approach is useful and assists in achieving the study objectives.

The population of the study is chosen from Al-Madinah Al-Munawarah regional municipality under the Ministry of Municipal and Rural Affairs. The number of populations is 550 employees (Website of amana-md.gov.sa). The main justification for choosing Al-Madinah Al-Munawarah regional municipality is the decision for creating green space in Al-Madinah regional municipality based on an agreement with the Ministry of Municipal and Rural Affairs. Another justification for selecting the employees of Al-Madinah AlMunawarah regional municipality is that they have 
responsibility to establish new green space and have also a plan to expand green spaces in other places in Al-Madinah Al-Munawarah. All 550 employees are already responsible for taking the green spaces into consideration in the new urban planning in Al-Madinah Al-Munawarah. They are also looking forward to providing green spaces for the new design in planning new cities in Al-Madinah Al-Munawarah, Saudi Arabia.

The sample of study is selected through the stratified random sampling technique. This type of sampling is selected when the study population is not homogeneous in its categories. By using this sampling technique, the population can be divided into small groups. The selected participants have similar characteristics. This study will use this type of sampling techniques in order to provide a representative sample of all categories based on their percentage in the original community. The sample of the study consisted of 231 persons including employees, managers, chief directors, lectures and departmental managers who work in AlMadinah Al-Munawarah regional municipality under the Ministry of Municipal and Rural Affairs. Then, 15 of the selected employees were interviewed and the qualitative data was collected through the interview.

\section{Data collection instruments}

The data of the present study was collected through two data collection instruments, namely, a questionnaire as well as an interview. The questionnaire was distributed online to all the participants of the study (240); then they were asked to fill out the questionnaire, and the researcher personally followed the process of distributing and filling out the questionnaires. In order to obtain the largest percentage of respondents, the researcher then sorted the questionnaires, (234) members responded, (3) questionnaires were excluded for not completing the answers of the questionnaire, the number of questionnaires which were valid for analysis became (231), representing (96\%) of the total number of the participants. However, the interviews were conducted with only 15 of the chosen employees.

The Statistical Package for Social Sciences (SPSS) version 24 was used for the analysis of the data collected through the survey. Due to the feature of online surveys, the data entry was completed by the participants. Once the data collection period was over, all of the responses were compiled in the SPSS file. The data set was filtered manually before running any tests. All of the invalid samples with missing values were removed from the data set. For example, if the participant missed one question, this survey was completely removed. The data analysis was carried out using means and standard deviations the Pearson Correlation Coefficient between the degree of each statement and the total degree of the axis to which it belongs. However, the qualitative data was analysed qualitatively through coding and then were converted into numerical data.

The qualitative data collected through interviews were qualitatively analyzed using thematic content analysis. Thematic content analysis aims to ascertain patterns of themes in the data of interview (Braun \& Clarke, 2006). This type of analysis is commonly used in analysing the data of interview because it is a flexible method that could be employed for both exploratory (where researchers do not have a clear idea of the patterns they are looking for) and deductive (where researchers know what they are searching for) research (Creswell, 2012).
In terms of how GIS was used for analysis, it is perhaps crucial to indicate that using Supervised pixel-based classification in ArcGIS Pro 2.6 with the help of classification wizard, the LULC Spatial distribution was extracted for all the required time periods, later on, only the urban coverage was delineated in different periods and the change over time statistically analyze within ArcGIS Pro.

Pixel-based classification is a traditional approach that decides what class each pixel belongs in on an individual basis. It does not take into account any of the information from neighboring pixels. It can lead to a salt and pepper effect in the classification results.

The object-based approach groups neighboring pixels together based on how similar they are in a process known as segmentation. Segmentation takes into account the color and the shape characteristics when deciding how pixels are grouped. Because this approach essentially averages the values of pixels and takes geographic information into account, the objects that are created from segmentation more closely resemble real-world features in your imagery and produces cleaner classification results.

Suitability for identifying the best proposed locations for new parks

This section highlights the suitability for identifying the best proposed locations for new parks as see Figure 2.

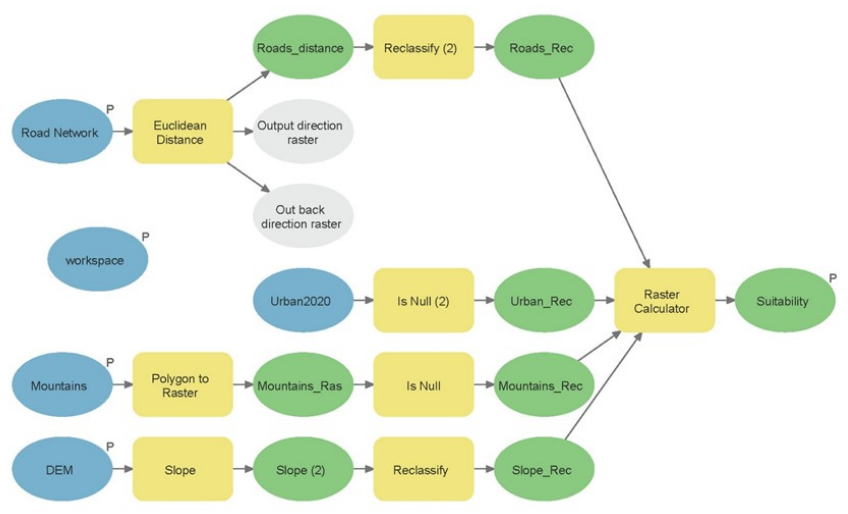

Figure 2. The cartographic model of the proposed new park locations

The location model is generally based within the ArcGIS environment to identify the different criteria involved in the suitability analysis process, and then convert those criteria into spatial layers, followed by the integration of those layers (or criteria together into a single layer) to produce a single layer that combines all those criteria to divide the investigated area (Al-Madinah Al-Munawarah) into ranges based on their suitability to propose new parks. As illustrated in the figure above, the model depends on a set of tools and processes that are implemented in the form of a flow chart starting with four inputs representing the spatial layers of the standards. However, the tools include classifying the criteria represented in raster cellular data through the use of reclassify, if the data is continuous such as the distance layer of roads and slope layer.

Moreover, if the data is binary, the Isnull tool is used to produce layers of Boolean value already classified. After that, all the classified criteria that came out of the reclassify process are collected through the Raster Calculator, which is similar to the Weighted sum process, where each criterion is weighed and the average is calculated for each cell in Al- 
Madinah Al-Munawarah based on the previous four criteria and their weights are considered, where the values of cells in the same location of the layers (criteria) are calculated. The identification/selection of the optimal location is based on the best criteria such as areas with as simple slopes as possible, areas near the main road network, undeveloped areas and excluding mountainous areas from selection.

After determining the criteria, their weights (the proportion of each criterion) are determined and those weights are introduced to calculate the weighted average at the level of the cells of the layers involved in the analysis. The final exit represents a layer of continuous raster type in which the value of each cell represents the appropriate amount of space to create proposed parks, through which the area can be classified into two final classifications (in terms of its suitability for development as parks).

\section{Results and Discussion}

This section presents the obtained results of the study as well as the discussion of these results.

The most suitable model for potential new green spaces

This section provides the findings of the study related to the most suitable model for potential new green spaces using GIS analysis for urban planning in Al-Madinah AlMunawarah, Saudi Arabia. This section answers the first question by identifying the most suitable model for potential new green spaces using GIS analysis for urban planning in $\mathrm{Al}$ -Madinah Al-Munawarah. To do so, the data obtained is reviewed and the percentages are also calculated for the most appropriate model at the municipal levels in Al-Madinah AlMunawarah. Then, the areas are ranked in a descending order based on the highest percentage of the best model as shown in Table 1.

Table 1 shows the area of green spaces models using GIS analysis for urban planning in Al-Madinah Al-Munawarah at the municipal level as well as their percentages. These areas are arranged according to their area and suitability for potential new green spaces using GIS analysis for urban planning. These are ordered from the most to least areas for new green spaces as follows: Quba (25.5\%), Al-Awali (21.2\%), Uhod (19.1\%), Al-Uyun (11.9\%), Al-Aqiq (11\%) AlBaidaa (10.8\%) Al-Haram (0.6\%), respectively.
Based on the analysis of the urban growth of Al-Madinah Al-Munawarah from 1972 to 2020, it is clear that that the most suitable model for potential new green spaces using GIS analysis for urban planning in Al-Madinah Al-Munawarah, Saudi Arabia is Quba. It is also revealed that the rate of urban growth in Al-Madinah Al-Munawarah was about 3.7 square kilometres per year, with an annual increase of $45 \%$ per annum from the base year in which the urban growth reached about $8.08 \mathrm{~km} 2$. Moreover, it is shown that the urban growth during various periods is characterized by variation, reaching the highest rate between 2000 and 2020, with an annual increase of about 4.52 square kilometres, while the lowest increase was registered in 1991-1971 with an annual increase of about 3.09 square kilometres.

Furthermore, Al-Awali municipality is one of the largest municipalities in terms of urban growth rates during the periods of the study, with an area of about 2.85 square kilometres to 90.72 square kilometres in just 48 years, while Al-Eyoon municipality registered the lowest rate in terms of urban growth as the rate of urban growth increased during the study period from an area of 7.55 square kilometres in 1972 to 39.74 square kilometres in 2020. Besides, the findings showed that most of the old urban growth was around the Prophet's Mosque and the urban growth continued to increase outside the centre of Al-Madinah Al-Munawarah, and thus the city has extended to big areas as it is today. It is also found that the urban increase was about $0.33 \%, 0.4 \%$ and 0.94\% during1972-1991, 1991-2000 and 2000-2020, respectively, i.e., the recent period was marked by a steady increase compared to previous ones.

Figure 4. is presented in this section to show the urban growth rates within municipalities during the investigated period in this study i.e. from 1972 to 2020.

Figure 4. the suitability of Al-Madinah Al-Munawarah to the proposed new parks.

Figure 4. shows the green space in Al-Madinah AlMunwarah, Saudi Arabia. The current green space in AlMadinah shows that the urban planning can be used in this area for developing new cities. The map shows that the suitable area takes the green colour. However, the nonsuitable areas are not considered to be green space.

Table 1. Urban growth rates within municipalities during the study period 1972-2020

\begin{tabular}{|c|c|c|c|c|c|c|c|}
\hline Municipality & & Area $(\mathrm{km} 2)$ & & & Mean & Suitable model & Rank \\
\hline & 1972 & 1991 & 2000 & 2020 & & & \\
\hline Quba & 3.96 & 44.58 & 58.37 & 97.37 & 51.07 & $25.5 \%$ & 1 \\
\hline Al-Awali & 2.85 & 29.50 & 46.44 & 90.72 & 42.38 & $21.2 \%$ & 2 \\
\hline Al-Haram & 0.07 & 1.10 & 1.29 & 1.65 & 1.03 & $0.5 \%$ & 7 \\
\hline Uhod & 4.12 & 22.19 & 37.41 & 88.84 & 38.14 & $19.1 \%$ & 3 \\
\hline Al-Uyun & 7.55 & 20.81 & 27.08 & 39.74 & 23.80 & $11.9 \%$ & 4 \\
\hline Al-Aqiq & 1.57 & 6.49 & 21.03 & 58.99 & 22.02 & $11.0 \%$ & 5 \\
\hline Al-Baidaa & 1.57 & 6.49 & 21.03 & 58.99 & 21.63 & $10.8 \%$ & 6 \\
\hline Total Area & 20.12 & 131.17 & 212.65 & 436.30 & 200.06 & $100.0 \%$ & \\
\hline Yearly Growth Rate (\%) & -- & 0.33 & 0.40 & 0.94 & 0.55 & & \\
\hline Yearly Growth Area (lm2) & -- & 6.50 & 8.44 & 20.57 & 11.84 & & \\
\hline
\end{tabular}




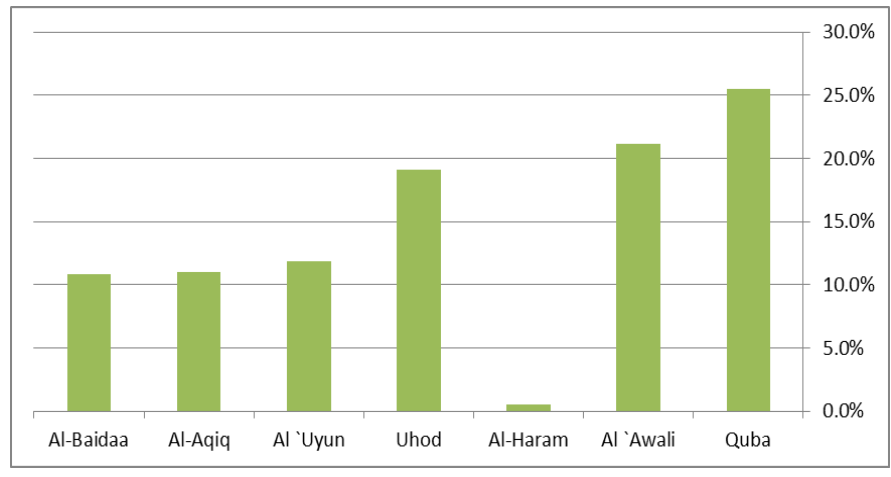

Figure 3. Diagram of urban growth rates within municipalities during the study period 1972-2020

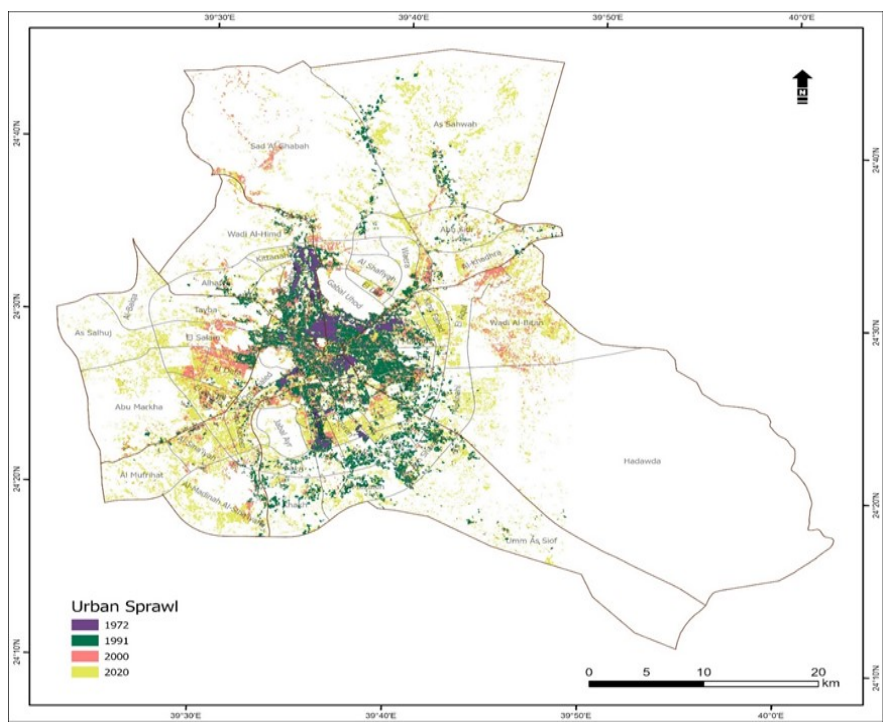

Figure 4. The distribution of the urban growth of Al-Madinah Al-Munawarah in 1972-2020

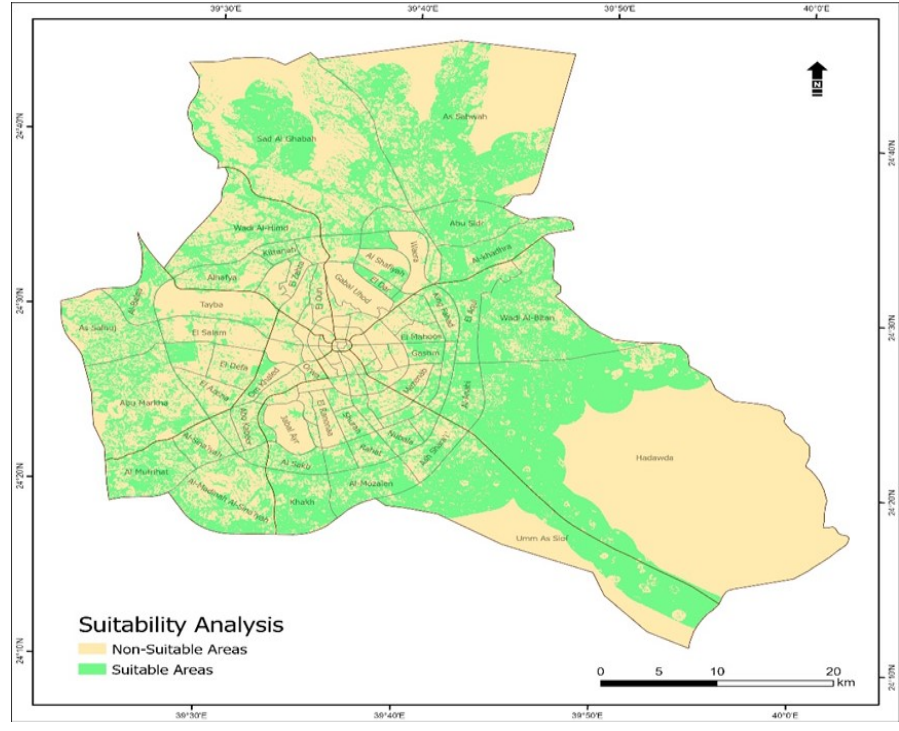

Figure 5. Suitability of Al-Madinah Al-Munawarah to the proposed new parks

The usefulness of the new designed green spaces

This section highlights the usefulness of the new designed green space for the residents of Al-Madinah Al-Munawarah, Saudi Arabia. It answers the second question by finding out how the new designed green spaces can be useful for the residents of Al-Madinah Al-Munawarah in Saudi Arabia. To this end, the data obtained from the interview are reviewed, and the frequencies and percentages are calculated. Then, the benefits of designing new green spaces for the residents will be ranked in a descending order based on the highest percentages, as shown in the Table 2.

Table 2 revealed the views of the participants regarding the benefits of designing new green spaces for the residents of Al-Madinah Al-Munawarah. Based on above findings, it is clear that the most prominent benefits of designing new green spaces for the residents of Al-Madinah Al-Munawarah are the provision of seats and seating area. These findings are in line with those of the study (White et al. 2013) which concluded that the population density is one of the main reasons for increasing green space through redesigning green spaces in new cities. There has been evidence which reveals that living in a greener environment could protect and promote and good health (Public Health England, 2020).

The challenges of designing a new green space area in AlMadinah Al-Munawarah

This section presents the results of the study regarding the challenges of designing a new green space area in $\mathrm{Al}$ Madinah Al-Munawarah, Saudi Arabia. It answers the third question by identifying the most challenges facing the design of a new green space in Al-Madinah Al-Munawarah, Kingdom of Saudi Arabia. To achieve this objective, the data obtained from the answers to question (15) of the interview questions are reviewed, and the frequency and percentages are calculated. Then, the challenges are ranked in a descending order based on the highest percentage as shown in the table 3 .

The results of Table 3 presents the views of the participants in terms of the most challenges of designing a new green space area in Al-Madinah Al-Munawarah, and these challenges came in a descending order based on the percentages as revealed.

Based on the above discussion, it is clear that the most prominent challenge facing the design of new green spaces in Al-Madinah Al-Muwarah, Saudi Arabia, is the weakness of the budget allocated to designing green spaces while the least prominent one is related to the use of modern technology for designing green spaces. This prominent challenge, i.e. insufficient budget for green spaces, could be presented to and resolved by the competent authorities in Al-Madinah AlMunawarah. In fact, the obtained findings of the present study are consistent with those found in (White et al., 2013) which concluded that the population density is one of the main reasons for increasing green spaces through redesigning green spaces in new cities.

The Development of urban green spaces in Al-Madinah

This section presents the findings of the study regarding the extent to which urban green spaces develop in AlMadinah Al-Munawarah and other parts of the world. Frequencies and percentages of the participants' answers are presented in the table 4.

Table 4 shows that $(46.7 \%)$ of the respondents believe that urban green spaces can develop in Al-Madinah AlMunawarah in the future, to a large degree while (20\%) of the participants believe that it can develop to some extent or to a weak degree. However, (6.7) \%) of the interviewee believe that it may not develop and other respondents $(26.7 \%)$ do not know the answer. Table (4) also shows that (53.3\%) of the respondents believe that urban green spaces can develop in other parts of the world in the future while $(13.3 \%)$ of them 
Table 2.The benefits of designing new green spaces for the residents of Al-Madinah Al-Munawarah

\begin{tabular}{llll}
\hline Answer & Frequencies & Percentages & Rank \\
\hline Providing adequate and open areas & 10 & $66.7 \%$ & 3 \\
security and safety aspects in designing green spaces & 5 & $33.3 \%$ & 7 \\
Designing good roads and paths & 7 & $46.7 \%$ & 5 \\
Providing seats and places to sit & 14 & $93.3 \%$ & 1 \\
Allocating places to provide public services & 12 & $80.0 \%$ & 2 \\
Allocating places for practicing various sports & 6 & $40.0 \%$ & 6 \\
Allocate places for entertainment & 9 & $60.0 \%$ & 4 \\
Allocating places for holding celebrations & 3 & $20.0 \%$ & 8 \\
\hline
\end{tabular}

believe that it can develop to some extent. Nevertheless, $(6.7 \%)$ of respondents believe that it can develop with a limited degree while no one believes that it may not develop in the future. Furthermore, $(26.7 \%)$ of the participants do not know the answer. These findings are consistent with the results of the studies (White et al. 2013; Safrilia \& Poerwoningsih, 2021) which concluded that green space could contribute to forming sustainable cities.

\section{Conclusion}

The present study examined the green spaces using GIS, the most suitable model for green spaces, the challenges facing the design of green spaces and the usefulness of green spaces for residents of Al-Madinah Al-Munawarah in Saudi Arabia. The findings of the study revealed the most suitable model for potential new green spaces using GIS analysis for urban planning in Al-Madinah Al-Munawarah, Saudi Arabia are Quba, Al-Awali, and Uhod, respectively. Moreover, the most prominent challenge facing the design of a new green space in Medina, Saudi Arabia, is the weakness of the budget allocated to designing green spaces. It is also shown that the most prominent benefits of designing new green spaces for the residents of Al-Madinah Al-Munawarah are the provision of seats and seating areas. Therefore, the participants pressed the importance of taking into account the provision of seats and seating places when designing green spaces. In terms of the potential of developing urban green spaces in Al-Madinah Al-Munawarah, a total of (46.7\%) of the respondents believe that urban green spaces can be developed, to a large degree, in Al-Madinah AlMunawarah in the future while (20\%) of them believe that it can develop to some extent or to a weak degree. Therefore, the study recommends that urban green spaces should be developed in Al-Madinah Al-Munawarah and the budget allocated to designing green spaces in Al-Madinah AlMunawarah should be also increased.

Table 3. Challenges of designing a new green space area in Al-Madinah Al-Munawarah

\begin{tabular}{|c|c|c|c|}
\hline Answer & Frequencies & Percentages & Rank \\
\hline Weakness of the budget allocated to designing green spaces & 13 & $86.7 \%$ & 1 \\
\hline Lack of engineering cadres in the field of urban planning & 8 & $53.3 \%$ & 4 \\
\hline The lack of awareness of the foundations of designing and planning green spaces & 7 & $46.7 \%$ & 5 \\
\hline The lack of engineering equipment specialized in designing green spaces & 5 & $33.3 \%$ & 6 \\
\hline The lack of modern technology for designing green spaces & 2 & $13.3 \%$ & 8 \\
\hline The repetition and lack of diversification in designing green spaces & 11 & $73.3 \%$ & 2 \\
\hline Neglecting the maintenance of green spaces periodically & 10 & $66.7 \%$ & 3 \\
\hline Neglecting the use of plants in the design of green spaces & 3 & $20.0 \%$ & 7 \\
\hline
\end{tabular}

Table 4. The development of urban green space in Al-Madinah Al-Munawarah in the future and other parts of the world

\begin{tabular}{llll}
\hline Question & Answer & Frequencies & Percentage \\
\hline How do you see the development of urban green & big development & 7 & $46.7 \%$ \\
space in Al-Madinah in the future? & to some extent development & 3 & $20.0 \%$ \\
& weak development & 3 & $20.0 \%$ \\
& no development & 1 & $6.7 \%$ \\
In other parts of the world & I don't know & 1 & $6.7 \%$ \\
& big development & 2 & $53.3 \%$ \\
& to some extent development & 1 & $13.3 \%$ \\
& weak development & 0 & $6.7 \%$ \\
& no development & 4 & $0.0 \%$ \\
& I don't know & $26.7 \%$ & \\
\end{tabular}




\section{References}

Abebe, M. T. \& Megento, T. L. (2017). Urban green space development using GIS-based multi-criteria analysis in Addis Ababa metropolis. Applied Geomatics, 9(4): 247-261.

Al-Ballaa, H., Comber, A. \& Smith, C. (2012). Distribution Pattern Analysis of Green space in Al-Madinah Using GIS, GIS Research UK 20 ${ }^{\text {th }}$ annual Conference, 2, 11-13 ${ }^{\text {th }}$ April 2012, Lancaster, pp 161-169. 2.

Barbosa, O., Tratalos, J., Armsworth, P., Davies, R., Fuller, R., Johnson, P. and Gaston, K. (2007). Who benefits from access to green space? A case study from Sheffield, UK, Landscape and Urban Planning, 83(3):187-195.

Barton, J., Pretty, J. (2010). What is the best dose of nature and green exercise for improving mental health? A multi-study analysis, Environmental Science \& Technology, 44(4):3947 3955.

Chiari, C. and Seeland, K., (2004), Are urban green spaces optimally distributed to act as places for social integration? Results of a geographical information system (GIS) approach for urban forestry research, Forest Policy and Economics, 6(6): 3-13.

Creswell, J. W. 2012. Educational research: Planning, conducting and qualitative research (4th ed.). Boston: Pearson Educaton.

Hansen, R., Frantzeskaki, N., McPhearson, T., Rall, E., Kabisch, N., Kaczorowska, A., Kain, J.-H., Artmann, M., Pauleit, S. (2015). The uptake of the ecosystem services concept in planning discourses of European and American cities. Ecosyst. Serv.12, 228-246.

Lam, K. C., Ng, S. L., Hui, W. C., \& Chan, P. K. (2005). Environmental quality of urban parks and open spaces in Hong Kong. Environmental Monitoring and Assessment, 111(4): 55-73.

McPhearson, T., Pickett, S.T.A., Grimm, N.B., Niemel, J., Alberti, M., Elmqvist, T., Weber, Dagmar, H., Juergen, B., Salman, Q. (2016). Advancing Urban Ecology toward a Science of Cities, BioScience, 55(3):198-212.

Metwaly, M., Abdalla, F., \& Taha, A. I. (2021). Hydrogeophysical Study of Sub-Basaltic Alluvial Aquifer in the Southern Part of Al -Madinah Al-Munawarah, Saudi Arabia. Sustainability, 13(17), 9841. MDPI AG. Retrieved from http://dx.doi.org/10.3390/ su13179841

Mobasheri, A., Pirotti, F. \& Agugiaro, G. (2020). Open-source geospatial tools and technologies for urban and environmental studies. Open geospatial data, softw. stand. 5, 5. https:// doi.org/10.1186/s40965-020-00078-2

Mytton, O., Townsend, N., Rutter, H. and Foster, C. (2012). Green space and physical activity: An observational study using Health Survey for England data, Health Place, 18(5)1034 - 1041. Neema, M.N., \& Ohgai, A. (2013). Multitype green-space modeling for urban planning using GA and GIS. Environment and Planning B: Planning and Design, 40(4): 447-473.

Panduro, T. E., \& Veie, K. L. (2013). Classification and valuation of urban green spaces-A hedonic house price valuation. Landscape and Urban Planning. 120, 119-128.

Pauleit, S., Hansen, R., Rall, E.L., Zölch, T., Luz, A.C., Szaraz, L., Tosics, I., Vierikko, K. (2017). Land use and land cover change detection through remote sensing approach: A case study of Kodaikanal taluk, Tamil nadu. International Journal of Geomatics and Geosciences, 1(2): 150-163.

Pojani, D., \& Maci, G. (2015). The Detriments and Benefits of the Fall of Planning: The Evolution of Public Space in a Balkan Postsocialist Capital. Journal of Urban Design, 20(2): 251-272.

Public Health England (2020). Improving access to greenspace: A new review for 2020, PHE publications.

Rahnama, M., \& Akbari, M. (2013). Analysis the principles and Dimensions of Urban Parks with point on green spaces in Mashhad city, Iran. American Journal of Engineering Research, 2(12): 136-143.

Rupprecht, C. D. D., \& Byrne, J. A. (2015). Informal urban green space: A trilingual systematic review of its role for biodiversity and trends in the literature. Urban Forestry \& Urban Greening,14(4):883-908.http://doi.org/10.1016 j.ufug.2015.08.009
Safrilia, A. and Poerwoningsih, D. (2021). Green space as potential for forming a sustainable city, 3rd International Seminar on Livable Space, IOP Conf. Series: Earth and Environmental Science.

The Report Saudi Arabia (2020). Available online at: https:// www.sidf.gov.sa.

White M.P., Alcock I, Wheeler, B.W., Depledge, M.H. (2013). Would you be happier living in a greener urban area? A fixedeffects analysis of panel data. Psychol Sci 24:920-928 